\title{
Forecasting the Electricity Demand and Market Shares in Retail Electricity Market Based on System Dynamics and Markov Chain
}

\author{
Qingyou Yan, ${ }^{1,2}$ Chao Qin $\mathbb{D}^{1},{ }^{1,2}$ Mingjian Nie $\mathbb{D}^{1},{ }^{1}$ and Le Yang $\mathbb{D}^{1,2}$ \\ ${ }^{1}$ School of Economics and Management, North China Electric Power University, Changping, Beijing 102206, China \\ ${ }^{2}$ Beijing Key Laboratory of New Energy and Low-Carbon Development, North China Electric Power University, \\ Changping, Beijing 102206, China
}

Correspondence should be addressed to Chao Qin; qinchao08@163.com

Received 29 August 2017; Revised 11 January 2018; Accepted 23 January 2018; Published 20 February 2018

Academic Editor: Quanxin Zhu

Copyright (C) 2018 Qingyou Yan et al. This is an open access article distributed under the Creative Commons Attribution License, which permits unrestricted use, distribution, and reproduction in any medium, provided the original work is properly cited.

\begin{abstract}
Due to the deregulation of retail electricity market, consumers can choose retail electric suppliers freely, and market entities are facing fierce competition because of the increasing number of new entrants. Under these circumstances, forecasting the changes in all market entities, when market share stabilized, is important for suppliers making marketing decisions. In this paper, a market share forecasting model was established based on Markov chain, and a system dynamics model was constructed to forecast the electricity consumption based on the analysis of five factors which are economic development, policy factors, environmental factors, power energy substitution, and power grid development. For a real application, the retail electricity market of Guangdong province in China was selected. The total, industrial, and commercial electricity consumption in Guangdong from 2016 to 2020 were predicted under different scenarios, and the market shares of the main market entities were analyzed using Markov chain model. Results indicated that the direct trading electricity would account for $70 \%$ to $90 \%$ of the total electricity consumption in the future. This provided valuable reference for the decision-making of suppliers and the development of electricity industry.
\end{abstract}

\section{Introduction}

The new round of electricity market reform (hereafter referred to as the "new electricity reform"), which was launched in 2015, included the reform of transmission and distribution price, the orderly deregulation of electricity generation and consumption plans, and the construction of electricity market. Among them, the deregulation of retail electricity market will bring about important welfare gains [1]. It will change the previous monopoly situation of power grid enterprises and provide opportunities for power generation companies, energy-saving service companies, industrial parks, and so on to create electricity sales companies and then join the market competition. Consequently, the cost of suppliers will be reduced and welfare gains will be brought to industrial enterprises and residential consumers [1]. In a word, the electricity market opening will have positive impact on economic growth and sustainability of power industries [2]. However, the reform of electricity market will inevitably change the current market structure and bring fierce competitions among suppliers. In this situation, it is of great significance to choose an appropriate method to predict the electricity market; an accurate prediction is conducive to the decision-making of suppliers, the development of power industry, and even the regional economic progress.

Nowadays, numerous scholars have carried out researches on various subjects relevant to the retail electricity market such as business model [3], pricing strategy [4], risk management $[5,6]$ and electricity price prediction [7-11]. In the matter of energy demand, various forecasting models have been applied to predict the electricity consumption. Traditional methods such as regression analysis (RA), time series analysis, nonparametric method, and small-sample adaptive hybrid model as well as soft computing techniques such as fuzzy logic, genetic algorithm, and neural networks are being extensively used [12-17]. Support vector regression, ant colony, and particle swarm optimization are new techniques being adopted for energy demand forecasting. Bottom up 
models such as MARKAL and LEAP are also being used at the national and regional level for energy demand management [18]. However, most of them are not appropriate for the forecast of deregulated electricity market of China because of their complicated input factors and the lack of available observation [19].

Markov chain is a stochastic process model with discreteness [20-22] and presents a quantitative analysis of the status of a system from one state to another. It has been widely used in the energy market, such as biogas production [23], wind power forecasting [24], crude oil import [25], and energy supply and demand [26], and has provided strong theoretical support for the price and demand forecast. Also, Markov chain can be used for macroeconomic analysis, for example, dynamic forecasting of industrial structure [27]; these analyses provide reference for China's industrial policy and other macro-development strategies. Moreover, Markov chain has a wide range of applications in the field of electricity. It has been used to analyze the reliability of power system, energy consumption structure, and the combination of electric load [28-32]. For instance, Sun and $\mathrm{Xu}$ presented an improved Grey-Markov chain model based on the wavelet transform to predict the energy production and consumption of China [26], Hong et al. optimized the size of renewable energy generations in a community microgrid using Markov model [33]. In conclusion, Markov chain is an effective method to predict the market volatility and describe the unobservable states. Since the reform and opening up, the economy in China has been in a state of rapid development. Therefore, this paper constructs a market share forecasting model based on Markov chain.

In order to forecast the market share of every market entity, deregulated electricity which means the part of electricity allowed to be sold by various suppliers in retail market needs to be figured out. According to the regulation of Chinese government, deregulated electricity is determined by industrial and commercial electricity consumption. Therefore, this paper uses system dynamics to predict the electricity consumption after the deregulation of retail market.

System dynamics is an interdisciplinary approach which combines the feedback and control of information, the decision-making theory, and computer technology. It is especially suitable for simulating the behavioral characteristics of nonlinear, high order, and complex time-varying systems [34] and is widely used in many fields. Energy systems are complex dynamic systems that are often associated with uncertain system behavior which is influenced by dynamic uncertainties, nonlinear relationships between system variables, interactive feedback loop, and so on [35]. The widespread deregulation leads to an ever-increasing size and complexity of energy systems. Under this climate, system dynamics as a system analysis approach is useful for organizing knowledge of the energy system in an efficient way. Recent studies applying system dynamics in energy system have focused on the alternative energy. For instance, Sisodia et al. (2015) explored solar energy as an alternative source of energy for the fulfillment of energy demand in India through a system dynamics approach [36]. Saavedra M. et al. (2018) identified the latest system dynamics contributions and trends related to the supply chain of renewable energy [37]. However, the influence factors of electricity consumption are complex and highly linked to each other. Due to the unique advantages of system dynamics in multivariate quantitative analysis and causal feedback, this paper constructed a system dynamics-based model to predict the electricity consumption.

To the best of our knowledge, system dynamics and Markov chain based methodology for the electricity demand and market shares, in Chinese context, is scarce in the energy literature. Therefore, this paper contributes to the existing literature by proposing the system dynamics and Markov chain based methodology that would have decision-making and policy implication for both the suppliers and government.

The rest of the paper is structured as follows: Section 2 determines the transition probability matrix by learning from relevant literature [38] and establishes the market share forecasting model based on the Markov chain; Section 3 analyzes current state and trading mode of the retail electricity market, constructs the system dynamics-based electricity consumption model by selecting five factors which are policy, environment, power energy substitution, macroeconomics, and power grid development, and sets six scenarios representing different economic development and industrial restructuring rates; Section 4 predicts electricity consumption and market shares in Guangdong province during 2016-2020 under different scenarios; Section 5 concludes the paper.

\section{Market Forecast Based on Markov Chain}

The reform of retail electricity market severely impacts the monopoly status of power grid enterprises resulting in a huge change in the structure of retail market. Using Markov chain model to predict and analyze the retail market is conducive to the identification and evasion of market risks facing the power grid enterprises. Consequently, it offers some grounds for power grid enterprises making investment decision about whether to establish their own electricity sales companies.

2.1. Markov Chain Method. A Markov chain is a sequence of random variables at different states, where each state value depends on the previous finite state. The range of these variables, that is, the set of all their possible values, is called the "state space." In every step of the Markov chain, the system can change from one state to another according to the probability distribution, and it can also maintain the current state. The change of state is called transition, and the probability related to state changes is called the transition probability.

Set random variable sequence as $\left\{X_{n}, n=1,2, \ldots\right\}$, and state space, $E$, is an countable or finite set, for any positive integer, $m, n$; if $i, j, i_{k} \in E(k=1,2, \ldots)$ and satisfy (1), the $\left\{X_{n}, n=1,2, \ldots\right\}$ is called Markov chain:

$$
\begin{aligned}
& P\left\{X_{n+m}=j \mid X_{1}=i_{1}, X_{2}=i_{2}, \ldots, X_{n-1}=i_{n-1}, X_{n}=i\right\} \\
& \quad=P\left\{X_{n+m}=j \mid X_{n}=i\right\} .
\end{aligned}
$$


Suppose that the conditional probability on the right side of the equal sign is independent of $n$; then (1) can de denoted as

$$
P\left\{X_{n+m}=j \mid X_{n}=i\right\}=p_{i j}(m),
$$

where $p_{i j}(m)$ is the transition probability from state $i$ to state $j$ after $m$ steps.

The transition probability, $p_{i j}(m)$, is only related to the number of steps $m$ but is not related to the initial time. If the number of steps $m=1$, the one step transition matrix of the Markov chain is expressed as follows:

$$
P\left\{X_{n+1}=j \mid X_{n}=i\right\}=p_{i j}(n) \quad i, j=1,2, \ldots, N .
$$

\subsection{Steps of the Retail Electricity Market Forecast}

2.2.1. Construction of Initial Transition Probability Matrix. In order to construct the initial transition probability matrix, the market shares of all suppliers need to be obtained and the electricity consumers switching from one supplier to another during the next period should be investigated. These could be acquired by compiling the electricity sales in a region. This paper assumes that the switching of electricity consumers will not change over time in the future.

Suppose $p_{i i}$ is the transition probability that the consumers of the $i$ th supplier continue to purchase electricity from that supplier. $p_{i j}$ indicates the probability from the $i$ th supplier to the $j$ th supplier. Then the transition probability matrix can be obtained:

$$
P=\left[\begin{array}{cccc}
p_{11} & p_{12} & \cdots & p_{1 N} \\
p_{21} & p_{22} & \cdots & p_{2 N} \\
\vdots & \vdots & \vdots & \vdots \\
p_{N 1} & p_{N 2} & \cdots & p_{N N}
\end{array}\right]
$$

The relation between the $N$-step state transition probability matrix $P(m)$ and the transition probability matrix $P$ is given by

$$
P(m)=P^{m}
$$

In the early days of the establishment of electricity sales company, the work investigating customer switching in the retail market is heavy and inefficient. An estimate method for initial transition probability matrix can be expressed as follows:

$$
X_{1}=\left[\begin{array}{cccc}
s_{1}^{(0)} & s_{2}^{(0)} & \cdots & s_{m}^{(0)} \\
s_{1}^{(1)} & s_{2}^{(1)} & \cdots & s_{m}^{(1)} \\
\vdots & \vdots & \ddots & \vdots \\
s_{1}^{(n-1)} & s_{2}^{(n-1)} & \cdots & s_{m}^{(n-1)}
\end{array}\right]
$$

$$
\begin{aligned}
X_{2} & =\left[\begin{array}{cccc}
s_{1}^{(1)} & s_{2}^{(1)} & \cdots & s_{m}^{(1)} \\
s_{1}^{(2)} & s_{2}^{(2)} & \cdots & s_{m}^{(2)} \\
\vdots & \vdots & \ddots & \vdots \\
s_{1}^{(n)} & s_{2}^{(n)} & \cdots & s_{m}^{(n)}
\end{array}\right], \\
M & =X_{1}^{T} X_{2}, \\
Y & =X_{1}^{T} X_{1}, \\
P & =Y^{-1} M .
\end{aligned}
$$

Through (6)-(10), the initial transition probability matrix can be obtained, and $\sum_{j=1}^{n} p_{i j}=1$.

2.2.2. Construction of Market Share Forecasting Model. Given the initial market share obtained by market investigation, the initial state transition probability matrix can be constructed:

$$
S^{(0)}=\left[p_{i}^{(0)}\right]_{1 \times n} .
$$

Set the $S_{i}^{(k)}=\left[p_{i}^{(k)}\right]_{1 \times n}$ as the market share of each supplier during the $k$ th period; then the market share forecasting model during the $k$ th period can be obtained as follows:

$$
\begin{aligned}
& S^{(1)}=S^{(0)} \cdot P, \\
& S^{(2)}=S^{(1)} \cdot P,
\end{aligned}
$$

$$
S^{(k)}=S^{(k-1)} \cdot P=S^{(0)} \cdot P^{k}
$$

2.2.3. Calculation of the Market Share in Equilibrium. When the market is in equilibrium, it is known that $S=S \cdot P$ according to (7); by combining it with the equation $\sum_{i=1}^{n} p_{i}=$ 1 , the unique solution to the market share of each supplier $p_{i}$ can be obtained.

\section{Market Analysis and Electricity Consumption Forecasting Model}

\subsection{Market Analysis}

3.1.1. Current Situation. On March 1, 2016, two power trading centers in Beijing and Guangzhou were set up and marked the reform of electricity market. These two national-level power trading centers are no longer the wholly owned subsidiaries of power grid enterprises; they provide nonprofit and normative services publicly and transparently for both sides of power trading under the government regulation.

According to a series of market access qualifications established by National Development and Reform Commission (NDRC) for suppliers, the total asset of a supplier corresponds to its electricity sales. For example, for a supplier whose registered capital is between 100 million and 200 million CNY, its annual electricity sales are between 3 and 6 


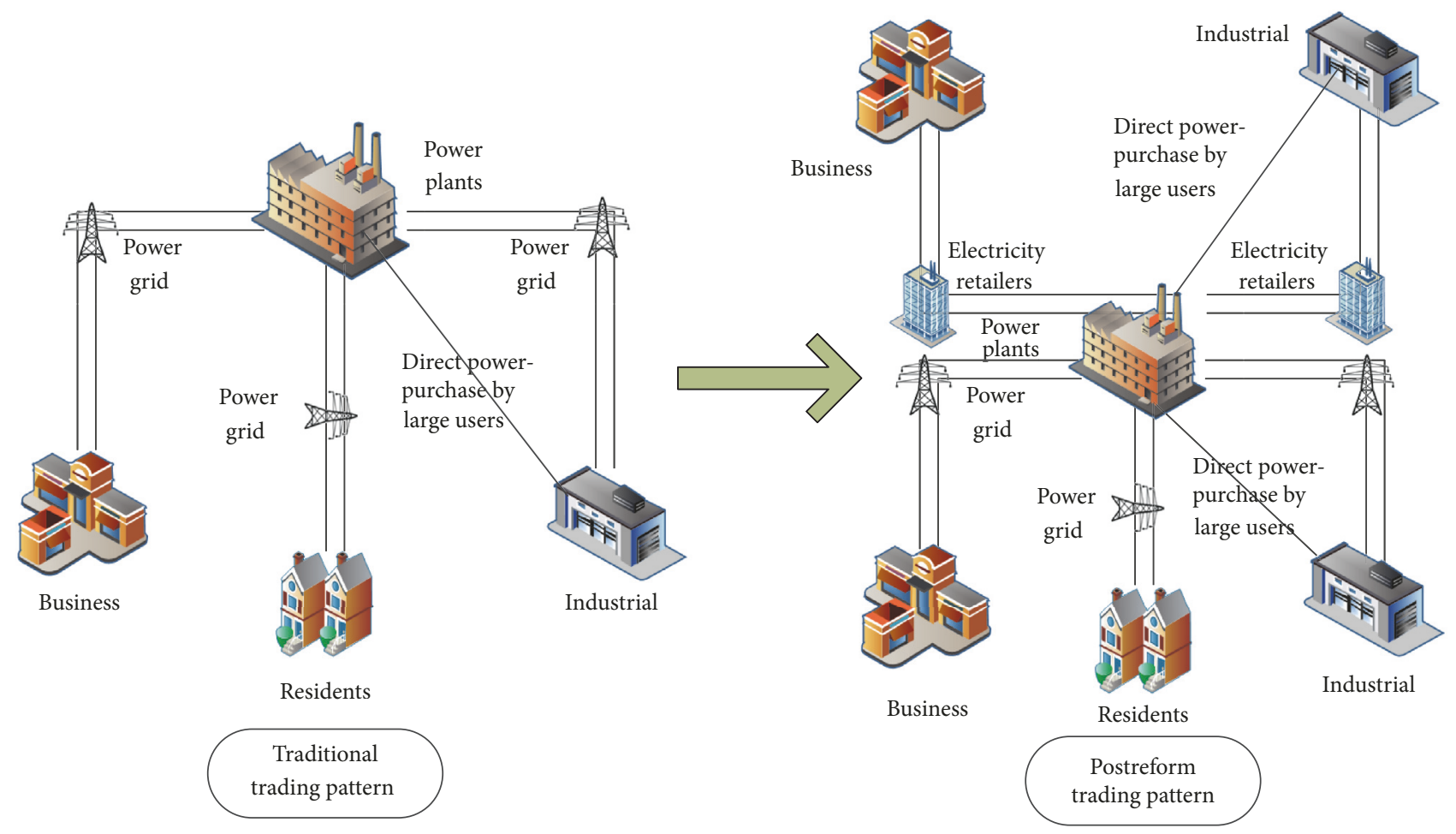

FIGURE 1: Diagram of the change in power trading modes.

billion $\mathrm{kWh}$. The main retail electric entities include power generation enterprises, power grid enterprises, industrial parks, and energy-saving service companies. The diversification of market entities means that the retail electricity market is getting severely competitive. Although new suppliers continually register or apply for registration, most of them have not started selling electricity, and the electricity sales are far from the upper limit.

3.1.2. Trading Modes. In 2016, the National Energy Bureau specified the types of trading modes in the context of the deregulation of retail electricity market. The first type is direct power-purchase; that is, large electricity consumers purchase power from the power generation enterprises directly. In the second type, entities purchase electricity using the suppliers as agents; for instance, large consumers or industrial parks choose a supplier to help purchase electricity. The third is that electricity consumers who do not participate in the trading market continue to purchase electricity from power grid enterprises. Power users can choose among these three ways. The emergence of suppliers as power purchasing agents and the expansion of direct power-purchase will affect the market scale of power grid enterprises. Figure 1 displays the trading modes of all types of consumers before and after the reform of retail market, respectively.

3.1.3. Relationship between the Deregulation and Electricity Consumption Forecast. After the deregulation of retail electricity market, the competition among various suppliers greatly affects the consumers' electricity behaviors. For industrial electricity with high proportion of electricity consumption, the fluctuation in electricity price leads to a difference in electricity consumption. Also, in the early stage of the deregulation, the electricity consumption is gradually liberalized; thus the growth rates of industrial and commercial electricity consumption affect the electricity sales of suppliers.

\subsection{Electricity Consumption Forecasting Model}

3.2.1. Model Construction. In the Electric Power Development "13th Five-Year" Plan released in November 2016, it is expected that in the next five years, China's total electricity consumption will increase by an average annual growth rate of $3.6-4.8 \%$, and the newly increased electricity consumption due to the power energy substitution is 450 billion $\mathrm{kWh}$. Under the circumstance of economic new normal, the forecast of the total electricity consumption is closely related to the (i) local economic development, (ii) policy factors (such as industrial restructuring), (iii) environmental impacts (measures to achieve the goal of energy saving and emission reduction), (iv) power energy substitution (replacing coal and gas by electricity on demand side), and (v) power grid development (enhancing transmission and distribution capacity). During the 13 th five-year period, policies such as "cutting overcapacity" and "restructuring" have caused tremendous pressure on coal, steel, and other heavy industries. All regions are facing the task of restructuring and industrial upgrading. Therefore, policy factors have the greatest impact on industrial electricity consumption. This 
paper decomposes the policy factors, environmental factors, power energy substitution factors, macroeconomic factors, and power grid development factors, respectively; the model is shown in Figure 2.

These five factors affect each other. For example, residential electricity price is a potential energy policy tool for improving energy efficiency; energy structure and economic growth impact the carbon emission; economy development increases the electricity consumption; and the increase in electricity consumption promotes the progress of industrial economy [39-44].

These factors individually and collectively have a great influence on electricity consumption. By analyzing the influence of various factors on the elasticity coefficient of electricity consumption and the growth rate of GDP, this paper forecasts the electricity consumption; the elasticity coefficient of electricity consumption is equal to the ratio of the total electricity consumption to GDP growth.
According to the impact of various factors on the total, industrial, and commercial electricity consumption, a system dynamics-based prediction model is constructed as shown in Figure 3.

The total electricity consumption is equal to the sum of initial consumption and the consumption increment during each period. Similarly, the industrial electricity consumption, commercial electricity consumption, nonfossil fuels consumption, and primary energy consumption are also calculated by summing up the initial consumption and consumption increment during each period. Moreover, the carbon emissions are equal to the sum of initial emissions and carbon emissions increments. The indexes such as industrial sales price and primary energy consumption growth rate affect policy factors, power grid development factors, and so on, therefore affecting the electricity consumption eventually. Main mathematical equations and logic of the model are listed as follows:

electricity consumption growth rate $=$ GDP growth $*$ elasticity coefficient of electricity consumption,

energy intensity effect $=\frac{(\text { primary energy consumption/GDP }- \text { the base year energy intensity) }}{\text { energy effect adjustment time }}$,

differential power pricing policy $=\frac{(\text { electricity price for high energy-consuming industry }- \text { industrial sales price })}{\text { industrial sales price }}$,

industrial restructuring rate

$=\frac{\text { the growth rate of the proportion of high energy-consuming industries in the total energy consumption }}{\text { industrial restructuring time }}$,

carbon emissions growth rate $=2.0411 *$ GDP growth $-1.1607 *$ energy intensity effect +0.1489

* population growth rate -0.0293

* the change rate of the shares of nonfossil fuels in primary energy consumption,

growth rate of electricity consumption $=$ GDP growth $*$ elasticity coefficient of electricity consumption,

The change rate of the shares of nonfossil fuels in primary energy consumption $=\frac{\text { nonfossil fuels consumption }}{\text { primary energy consumption }}$

elasticity coefficient of electricity consumption = IF THEN ELSE (power grid development factors

$\leq 0$, policy factors + environmental factors + power energy substitution factors, Policy factors

+ environmental factors + power energy substitution factors - power grid development factors)

Using the data from 2015 as initial values, and based on factors such as expected consumption expenditure growth rate, nonfossil fuels consumption growth rate, and primary energy consumption growth rate, this paper forecasts the electricity consumption in the empirical analysis.

3.2.2. Scenario Setting. In the prediction model displayed in Figure 3, the energy intensity is the ratio of primary energy consumption to GDP; the base year is set to be
2015; the industrial restructuring is the proportion of high energy-consuming industries' energy consumption to the total energy consumption. In addition, carbon emissions growth rate $=2.0411 *$ average annual growth rate of national economy $-0.0293 *$ the shares of nonfossil fuels in primary energy consumption $-1.1607 *$ energy intensity effect + $0.1489 *$ population size effect [45]. Due to the acceleration of the construction of power grids throughout the country, in the future, the power grid development is not expected 

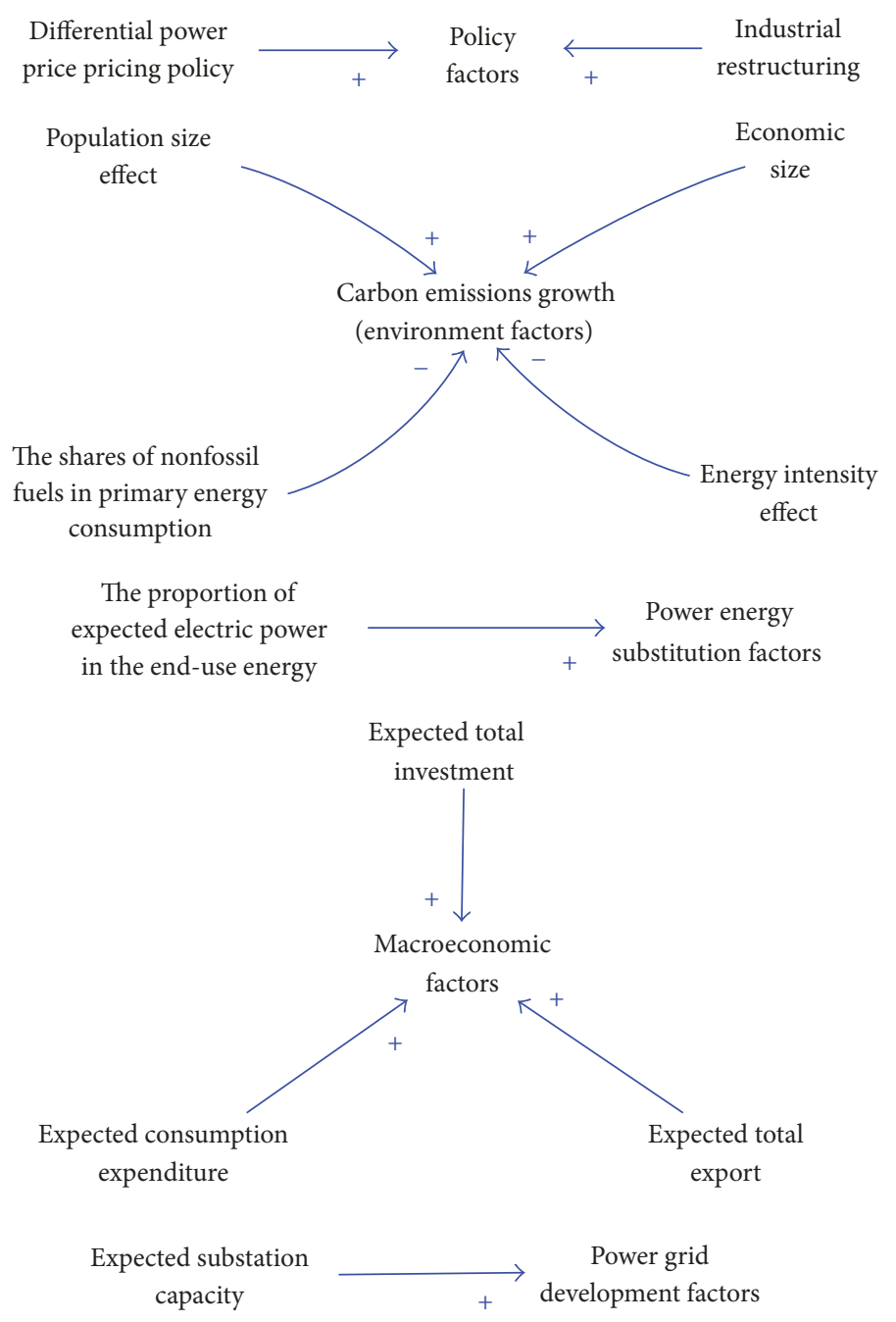

Figure 2: Diagram of decomposition and feedback of every factor.

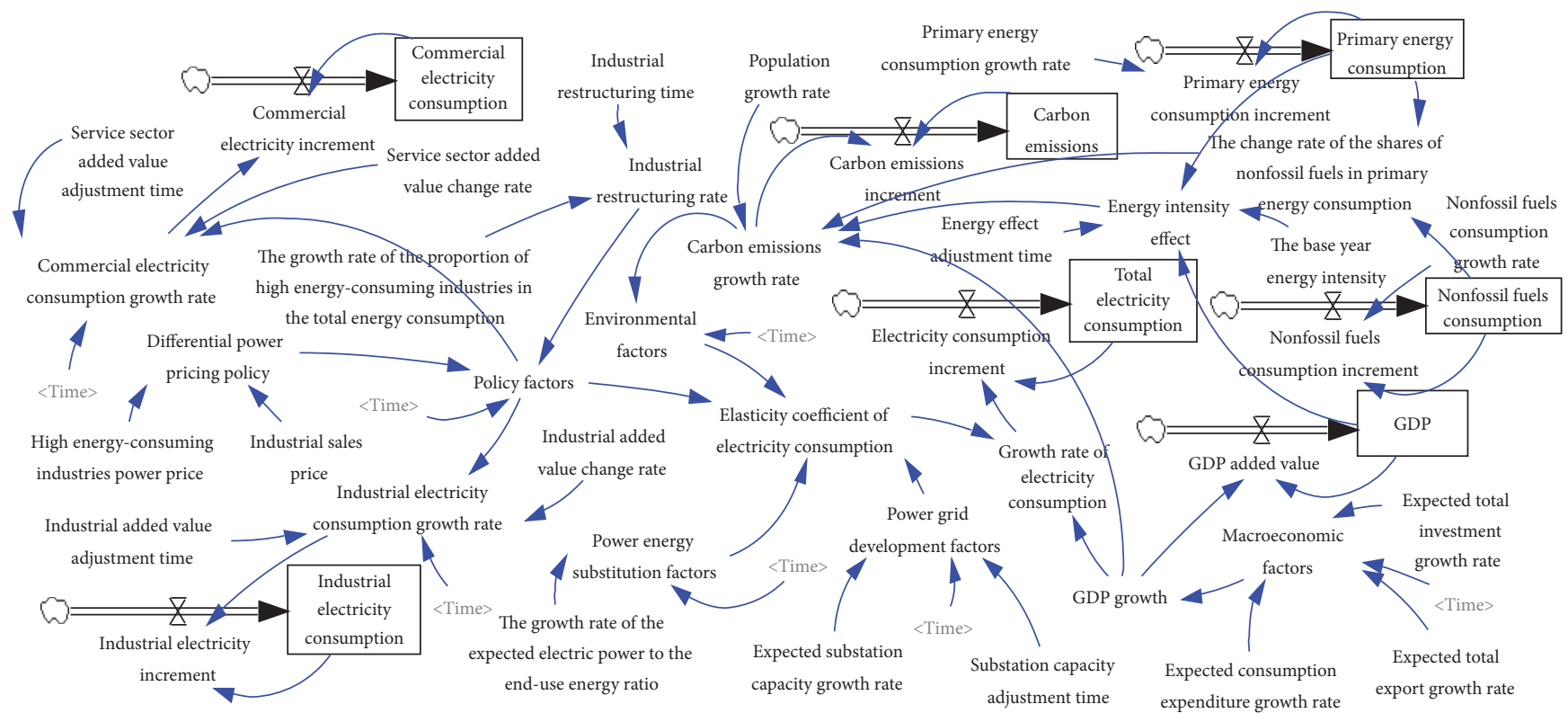

FIGURE 3: Electricity consumption prediction model. 
TABLE 1: Parameter determination under different scenarios.

\begin{tabular}{|c|c|c|c|c|c|c|}
\hline Scenarios & $\begin{array}{l}\text { Consumption } \\
\text { growth rate (\%) }\end{array}$ & $\begin{array}{c}\text { Investment growth } \\
\text { rate }(\%)\end{array}$ & $\begin{array}{l}\text { Export growth rate } \\
(\%)\end{array}$ & $\begin{array}{c}\text { Industrial } \\
\text { restructuring rate } \\
(\%)\end{array}$ & $\begin{array}{c}\text { Expected electric } \\
\text { power ratio growth } \\
\text { rate }(\%)\end{array}$ & $\begin{array}{c}\text { Nonfossil fuels } \\
\text { share growth rate } \\
(\%)\end{array}$ \\
\hline 1 & 7.1 & 8.8 & -0.7 & 2.74 & 1.0 & 1.63 \\
\hline 2 & 9.2 & 11.8 & 2.7 & 3.66 & 0.8 & 2.08 \\
\hline 3 & 9.2 & 11.8 & 2.7 & 2.74 & 1.0 & 1.63 \\
\hline 4 & 8.7 & 9.6 & 1.6 & 1.08 & 1.2 & 1.11 \\
\hline 5 & 8.7 & 9.6 & 1.6 & 2.74 & 1.0 & 1.63 \\
\hline 6 & 8.7 & 9.6 & 1.6 & 3.66 & 0.8 & 2.08 \\
\hline
\end{tabular}

Note. Expected electric power ratio is short for the expected electric power to the end-use energy ratio.

to hinder the growth of electricity consumption, and the influence of power energy substitution factors will increase year by year.

During the 13th five-year period, the elasticity coefficient of electricity consumption and the influence weights of various macroeconomic factors will change. Therefore, this paper analyzes the industrial, commercial, and total electricity consumption increment under different weights of various factors by conducting scenario analysis. Accordingly, the electricity consumption in Guangdong province during 2016-2020 is forecasted in the next section.

According to China's 13th Five-Year Plan, the economy is expected to maintain a medium-to-high level of growth, and the corresponding average growth rate of GDP is $7 \%$. Taking into consideration the implementation of the Belt and Road and the supply-side structural reform, this paper sets different contribution rates for export, consumption, and investment (three engines that drive the national economy) and adjusts the industrial restructuring rate, the growth rate of the expected electric power to the end-use energy ratio, the carbon emissions growth rate, and other factors. Subsequently, scenarios under different economic development and industrial restructuring rates are conducted to forecast the total electricity consumption. Then market shares of power grid companies and other electricity sales companies who participate in direct power trading are forecasted in the case of a moderate-speed economic development and a moderate industrial restructuring.

\section{Empirical Study}

\subsection{Electricity Consumption Forecast}

4.1.1. Assumptions. In this paper, the electricity market trading in Guangdong province is used as an example. Guangdong province began a series of pilots on direct electricitypurchase for large consumers in 2006. The annual trade electricity approximated 200 million kWh in the next few years. Subsequently, in 2013, Guangdong expanded the pilot scale and gradually increased the proportion of direct trading electricity to the electricity generation for a few years. As for now, the participation of suppliers and the conduct of electricity auction in trading centers have led to more abundant market entities that participate in the direct power trading and more diverse trading modes since 2016.
In the ensuing sections, market share of direct trading in which suppliers are major participants is predicted; the assumptions are made before forecast as follows.

Assumption 1. In the process of the deregulation of retail electricity market, the retail side is gradually liberalized according to the consumer types which are large industrial consumers, general industrial consumers, commercial consumers, residential consumers, and others. The power supplied for agricultural production, residents, and other important consumers involves the vital interests of the masses. And these kinds of consumers have not participated in the direct trading or purchase electricity from suppliers. Therefore, we assume that their electricity is provided by power grid enterprises, and we have a term for this sort of thing-guaranteed service. Also, we assume that electricity market competition only exists in industrial and commercial electricity.

Assumption 2. In March 2016, National Energy Board issued the relevant suggestions about electricity market construction. This paper was planned to achieve the comprehensive deregulation of local industrial electricity consumption in 2018 and achieve the comprehensive deregulation of local commercial electricity consumption in 2020. Therefore, this paper uses the year of 2020 as the node, forecasts the direct trading electricity as well as industrial and commercial electricity consumption from 2016 to 2020, and subsequently predicts the future market share.

Assumption 3. Market entities that directly trade with power generation enterprises include power grid enterprises, large electricity consumers, and retail electric suppliers. Retail electric suppliers and large consumers are both involved in the direct electricity trading by signing annual long-term agreement and monthly bidding. Suppliers are predominant in future direct power trading. Therefore, we assume that suppliers and large consumers are involved in the market competition as direct trading participants.

4.1.2. Forecast. According to the forecasting models in the second section and the analysis of economic and energy development data in Guangdong over the years, the values of parameter variables under scenarios 1-6 are assigned, respectively, as shown in Table 1 . The growth rates of consumption, 

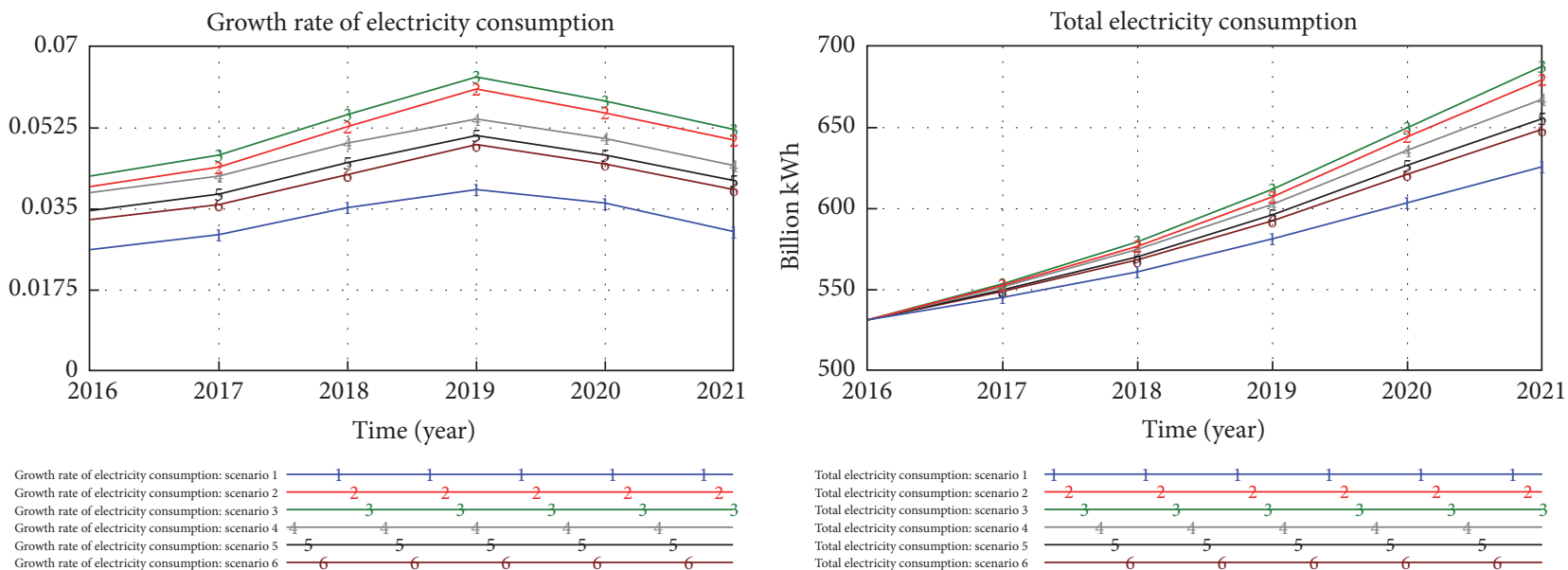

FIGURE 4: Electricity consumption growth rate and total electricity consumption under different scenarios.

investment, and export reflect the economic development. The industrial restructuring rate is mainly based on the change in the added value of service sector to the gross regional product ratio and reflects the policy factors. Scenario 1 represents the case of a moderate-speed economic development and a moderate industrial restructuring, scenario 2 represents the case of a high-speed economic development and a fast industrial restructuring, scenario 3 represents the case of a high-speed economic development and a moderate industrial restructuring, scenario 4 represents the case of a medium-high-speed economic development and a slow industrial restructuring, scenario 5 represents the case of a medium-high-speed economic development and a moderate industrial restructuring, and scenario 6 represents the case of a medium-high-speed economic development and a moderate industrial restructuring. The data mainly comes from the Guangdong Statistical Yearbook 2016.

From the Statistics Bureau of Guangdong Province, in 2016, the total electricity consumption growth in Guangdong province rose by $5.6 \%$; the consumption, investment, export growth rates were $10.2 \%,-1.3 \%$, and $10 \%$, respectively; the ratio of service sector added value to gross regional product increased from $50.8 \%$ in 2015 to $52.1 \%$; and the industrial restructuring rate grew by $2.56 \%$ year on year. We can see that the parameters set and the resulting forecasts match scenario 3 ; consequently, the effectiveness of the model can be verified. In addition, due to the fluctuation in economic data every year, conditions set in each scenario are the average annual data during the forecasting.

Through the analysis in Figure 4, it can be known that the economic growth rate greatly affects the electricity consumption growth rate; however, it is unrealistic for Guangdong province to achieve high-speed growth under the economic new normal. The industrial restructuring also affects the electricity consumption; according to statistics in 2015, six high energy-consuming industries accounted for $33.3 \%$ of the total energy consumption, and their electricity consumption accounts for $27.8 \%$ of the total. Therefore, we forecast the total, industrial, and commercial electricity consumption in the case of medium-high economic development and moderate industrial restructuring, as shown in Figure 5.

\subsection{Market Share Forecast}

4.2.1. Construction of Transition Probability Matrix. The construction of transition probability matrix is the key to the accuracy of the market forecast when using Markov chain model and it is also a difficulty. In the general market forecast, the liquidity of customers among enterprises is determined mainly through investigating the proportion of customers who switch to other enterprises to the total customer groups each year, and the final market share of each enterprise is obtained using Markov chain model.

However, at the beginning of the reform of retail electricity market, the market has just begun to be open to other social capitals. Suppliers that possess the right of distribution network management as well as independent suppliers have just been set up. As a result, relatively stable market liquidity has not been reached. We believe that the suppliers will gradually occupy the original market share of power grid enterprises for the coming period of time and ultimately achieve a stabilized market state. Therefore, when analyzing the market share of the retail market, economic development and policy factors such as industrial restructuring should both be taken into consideration. Table 2 lists the statistics and forecast of direct trading electricity and electricity sales of power grid under scenario 1 .

Based on the ratios of every year in Table 2, we solve (6)-(10) using MATLAB. The initial transfer probability matrix is obtained as

$$
P=\left[\begin{array}{cc}
0.896 & 0.104 \\
0.0157 & 0.9843
\end{array}\right] \text {. }
$$

4.2.2. Market Share in Equilibrium. We assume that the market share of power grid companies and direct trading in equilibrium can be expressed as $S=\left(s_{1}, s_{2}\right)$; besides, $s_{1}+s_{2}=$ 1. Through the equation $S \cdot P=S$, it is calculated out that 
TABLE 2: Direct trading electricity and grid's electricity sales from 2013 to 2020 in Guangdong province under scenario 1.

\begin{tabular}{|c|c|c|c|c|c|}
\hline Time & Total electricity consumption (TWh) & Grid's electricity sales (TWh) & Ratio (\%) & Direct trading electricity (TWh) & Ratio (\%) \\
\hline 2013 & 483.0 & 480.6 & 99.3 & 2.4 & 0.7 \\
\hline 2014 & 523.5 & 508.5 & 96.0 & 15.0 & 4.0 \\
\hline 2015 & 531.1 & 508.4 & 94.6 & 22.7 & 5.4 \\
\hline 2016 & 549.0 & 507.0 & 92.3 & 42.0 & 7.7 \\
\hline 2017 & 568.4 & 483.8 & 85.1 & 84.6 & 14.9 \\
\hline 2018 & 591.7 & 259.4 & 43.8 & 332.3 & 56.2 \\
\hline 2019 & 618.7 & 269.8 & 43.6 & 348.9 & 56.4 \\
\hline 2020 & 648.7 & 284.0 & 43.8 & 364.7 & 56.2 \\
\hline
\end{tabular}

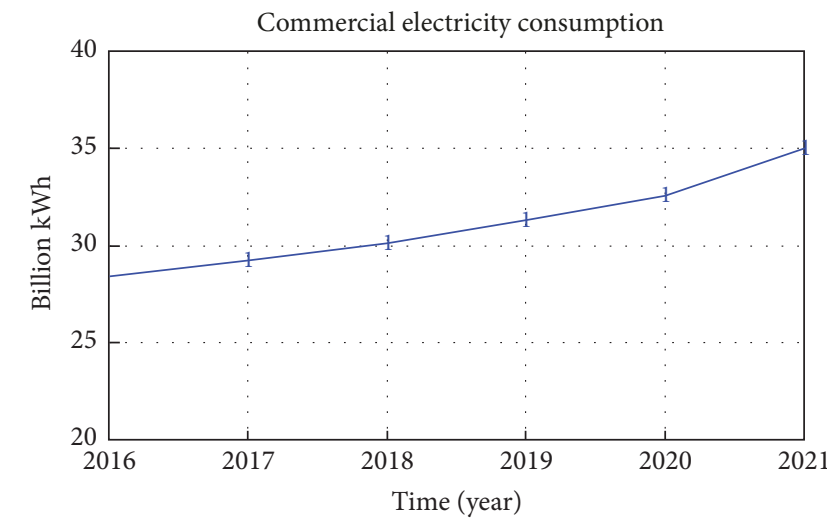

Commercial electricity consumption: scenario $5 \begin{array}{lllllllllll} & -1 & 1 & 1 & 1 & 1 & 1 & 1 & 1\end{array}$

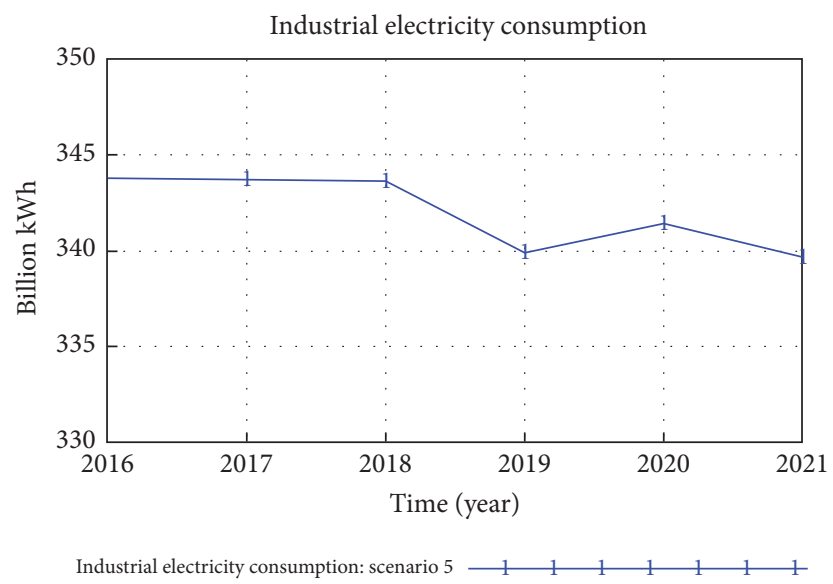

FIGURE 5: The total, industrial, and commercial electricity consumption forecast.

$s_{1}=13.12 \%, s_{2}=86.88 \%$ under scenario 1 . That means, with the deregulation of industrial and commercial electricity consumption in the future, the guaranteed service of power grid companies will account for $13.12 \%$ of the total electricity sales. Table 3 displays the ratio of the grid's electricity sales and the direct trading electricity.

From the scenario analysis above (Table 3), a slowdown in economy and acceleration of industrial restructuring will both result in a decline in the ratio of the power grids' electricity sales and an increase in the proportion of direct trading electricity. On the whole, the market share of direct trading in which suppliers predominantly participate is between $70 \%$ and $90 \%$. Therefore, there is a huge bonus for suppliers because of the reform of retail electricity market and the deregulation of electricity consumption for users at all voltage classes.

As for direct power trading before 2016, it mainly represents the direct power-purchase between large industrial consumers and power generation enterprises. In 2016, with the emergence of suppliers and the start of retail electricity business, it gradually transferred into the mode in which suppliers directly trade with power generation companies on behalf of consumers. As an instance, Guangdong province has announced a number of batches of directories about suppliers, and the suppliers trade with power generation companies on behalf of large consumers by negotiating bilateral agreements with power generation companies and/or centrally bidding in the power trading market. They will support most of electricity in the direct trading.

Compared with electricity auction, annual long-term agreement in the direct power trading can be signed by two groups of market entities. One group of entities is some large industrial consumers and industrial parks; they purchase electricity directly, start their own electricity sales companies, and then supply electricity to industrial firms or parks alone. The other is the emerging suppliers; most industrial and commercial users and industrial parks would be attracted by their professional services and appropriate price. As a consequence, suppliers are going to occupy a more important position in the direct power trading.

\section{Conclusion}

In this paper, Guangdong province was chosen as the research object, and the future retail electricity market was forecasted through the use of Markov chain and system dynamics method. In detail, the future market share of power grid companies that provide guaranteed services and the direct trading in which the retail electricity suppliers are mainly involved were analyzed, respectively. Scenario analysis was conducted using economic growth and industrial restructuring as separators; the total, industrial, and commercial electricity consumption under different scenarios were forecasted; and the resulting influences on the future market share 
TABLE 3: Comparison between the market share of the grid's electricity sales and that of direct transaction under different scenarios.

\begin{tabular}{lcccc}
\hline Scenarios & Economic growth & Industrial restructuring rate & Market share of power grid companies (\%) & Market share of direct trading (\%) \\
\hline 1 & Moderate-speed & moderate & 13.12 & 86.88 \\
2 & High-speed & fast & 21.95 & 78.05 \\
3 & High-speed & moderate & 30.57 & 69.43 \\
4 & Medium-high-speed & low & 24.94 & 75.06 \\
5 & Medium-high-speed & moderate & 16.16 & 83.84 \\
6 & Medium-high-speed & fast & 8.49 & 91.51 \\
\hline
\end{tabular}

were analyzed. Overall, in the context of full liberalization of industrial and commercial electricity consumption, the direct trading electricity will account for $70 \%$ to $90 \%$ of the total electricity consumption in the future.

With the deepening of electricity market reform and the deregulation of residential electricity in the future, it surely will create more profit. As one can imagine, not only the power generators and power grids, but also private capitals will establish independent electricity sales companies based on their own advantages to share the huge reform benefits. In this paper, we mainly considered the ratio of the overall electricity sales of suppliers and the guaranteed electricity sales of power grid companies. Exploring the customer switching between suppliers and the change in market share will be an effective way to study the market behavior of suppliers in the future.

\section{Conflicts of Interest}

The authors declare that there are no conflicts of interest regarding the publication of this paper.

\section{Acknowledgments}

This work was supported by "Special Items Fund of Beijing Municipal Commission of Education" (16JDGLB023) and the "Fundamental Research Funds for the Central Universities" (2017XS105).

\section{References}

[1] P. M. Sebastián and S. P. Eduardo, "Alternative policies for the liberalization of retail electricity markets in Chile," Utilities Policy, 2017.

[2] D. Streimikiene and I. Siksnelyte, "Sustainability assessment of electricity market models in selected developed world countries," Renewable \& Sustainable Energy Reviews, vol. 57, pp. 7282, 2016.

[3] D. Tayal and V. Rauland, "Future business models for Western Australian electricity utilities," Sustainable Energy Technologies and Assessments, vol. 19, pp. 59-69, 2017.

[4] F. Gökgöz and M. E. Atmaca, "Portfolio optimization under lower partial moments in emerging electricity markets: Evidence from Turkey," Renewable \& Sustainable Energy Reviews, vol. 67, pp. 437-449, 2017.

[5] L. Bartelj, D. Paravan, A. F. Gubina, and R. Golob, "Valuating risk from sales contract offer maturity in electricity market,"
International Journal of Electrical Power \& Energy Systems, vol. 32, no. 2, pp. 147-155, 2010.

[6] X. Kong, P. Li, Z. Yan et al., Stress testing on electricity market with retail transactions opened, 2016.

[7] H.-T. Pao, "Forecasting electricity market pricing using artificial neural networks," Energy Conversion and Management, vol. 48, no. 3, pp. 907-912, 2007.

[8] P. Mandal, T. Senjyu, N. Urasaki, T. Funabashi, and A. K. Srivastava, "A novel approach to forecast electricity price for PJM using neural network and similar days method," IEEE Transactions on Power Systems, vol. 22, no. 4, pp. 2058-2065, 2007.

[9] P. Bento, J. Pombo, M. Calado, and S. Mariano, "A bat optimized neural network and wavelet transform approach for short-term price forecasting," Applied Energy, vol. 210, pp. 88-97, 2018.

[10] D. Liu, Y. Wei, S. Yang, and Z. Guan, "Electricity price forecast using combined models with adaptive weights selected and errors calibrated by hidden Markov model," Mathematical Problems in Engineering, vol. 2013, Article ID 648101, 2013.

[11] O. Wu, T. Liu, B. Huang, and F. Forbes, "Predicting electricity pool prices using hidden Markov models," IFAC-PapersOnLine, vol. 28, no. 8, pp. 343-348, 2015.

[12] Q. Zhu, "pth moment exponential stability of impulsive stochastic functional differential equations with Markovian switching," Journal of The Franklin Institute, vol. 351, no. 7, pp. 3965-3986, 2014.

[13] G. K. F. Tso and K. K. W. Yau, "Predicting electricity energy consumption: A comparison of regression analysis, decision tree and neural networks," Energy, vol. 32, no. 9, pp. 1761-1768, 2007.

[14] U. Kumar and V. K. Jain, “Time series models (Grey-Markov, Grey Model with rolling mechanism and singular spectrum analysis) to forecast energy consumption in India," Energy, vol. 35, no. 4, pp. 1709-1716, 2010.

[15] Q. Zhu and H. Wang, "Output feedback stabilization of stochastic feedforward systems with unknown control coefficients and unknown output function," Automatica, vol. 87, pp. 166-175, 2018.

[16] P. K. Wesseh Jr. and B. Zoumara, "Causal independence between energy consumption and economic growth in Liberia: Evidence from a non-parametric bootstrapped causality test," Energy Policy, vol. 50, pp. 518-527, 2012.

[17] M. Meng, Y. Fu, H. Shi, and X. Wang, "A small-sample adaptive hybrid model for annual electricity consumption forecasting," Mathematical Problems in Engineering, vol. 2017, Article ID 7427131, 2017.

[18] L. Suganthi and A. A. Samuel, "Energy models for demand forecasting-a review," Renewable \& Sustainable Energy Reviews, vol. 16, no. 2, pp. 1223-1240, 2012. 
[19] N.-M. Xie, C.-Q. Yuan, and Y.-J. Yang, "Forecasting China's energy demand and self-sufficiency rate by grey forecasting model and Markov model," International Journal of Electrical Power \& Energy Systems, vol. 66, pp. 1-8, 2015.

[20] Q. Zhu and T. Prieto-Rumeau, "Bias and overtaking optimality for continuous-time jump Markov decision processes in Polish spaces," Journal of Applied Probability, vol. 45, no. 2, pp. 417-429, 2008.

[21] B. Wang and Q. Zhu, "Stability analysis of Markov switched stochastic differential equations with both stable and unstable subsystems," Systems \& Control Letters, vol. 105, pp. 55-61, 2017.

[22] R. Song and Q. Zhu, "Stability of linear stochastic delay differential equations with infinite Markovian switchings," International Journal of Robust and Nonlinear Control, vol. 28, no. 3, pp. 825837, 2018.

[23] M. Bojesen, H. Skov-Petersen, and M. Gylling, "Forecasting the potential of Danish biogas production - Spatial representation of Markov chains," Biomass \& Bioenergy, vol. 81, no. 2, pp. 462472, 2015.

[24] A. Carpinone, M. Giorgio, R. Langella, and A. Testa, "Markov chain modeling for very-short-term wind power forecasting," Electric Power Systems Research, vol. 122, pp. 152-158, 2015.

[25] C. Zhang, H. Chen, X. Yan, R. Zhao, Q. Zhang, and Y. Zhang, "Markov chain and oil import opportunity decision," Journal of China University of Petroleum, vol. 34, no. 5, pp. 183-174, 2010.

[26] W. Sun and Y. Xu, "Research on China's energy supply and demand using an improved Grey-Markov chain model based on wavelet transform," Energy, vol. 118, pp. 969-984, 2017.

[27] S. Altug, B. Tan, and G. Gencer, "Cyclical dynamics of industrial production and employment: Markov chain-based estimates and tests," Journal of Economic Dynamics \& Control, vol. 36, no. 10, pp. 1534-1550, 2012.

[28] L. Min, H. Jiang, Y. Huang, and X. Song, "Combination Load Forecast with Time-varying Weights Based on Markov Chain," in Proceedings of the Chinese Society of Universities for Electric Power System \& Its Automation, vol. 23, pp. 131-134, 2011.

[29] W. G. Zhao, J. Z. Wang, and H. Y. Lu, "Combining forecasts of electricity consumption in China with time-varying weights updated by a high-order Markov chain model," Omega , vol. 45, pp. 80-91, 2014.

[30] X. Wang and D. Niu, "Forecasting on Competition Ability of Electric Power Resource Based on Markov Chain," Modern Electric Power, vol. 1, pp. 94-97, 2004.

[31] W. Wu, F. Wen, Y. Xue, X. Zhao, and R. Hu, "A Markov chain based model for forecasting power system cascading failures," Dianli Xitong Zidonghua/Automation of Electric Power Systems, vol. 37, no. 5, pp. 29-37, 2013.

[32] Y. Wang, X. Han, Y. Ding, and J. Shen, "Markov chain-based rapid assessment on operational reliability of power grid," Dianwang Jishu/Power System Technology, vol. 37, no. 2, pp. 405410, 2013.

[33] Y.-Y. Hong, W.-C. Chang, Y.-R. Chang, Y.-D. Lee, and D.-C. Ouyang, "Optimal sizing of renewable energy generations in a community microgrid using Markov model," Energy, vol. 135, pp. 68-74, 2017.

[34] Q. Zhu and J. Cao, "Stability of Markovian jump neural networks with impulse control and time varying delays," Nonlinear Analysis: Real World Applications, vol. 13, no. 5, pp. 2259-2270, 2012.

[35] M. Mutingi, C. Mbohwa, and V. P. Kommula, "System dynamics approaches to energy policy modelling and simulation," Energy Procedia, vol. 141, pp. 532-539, 2017.
[36] G. S. Sisodia, M. Sahay, and P. Singh, "System Dynamics Methodology for the Energy Demand Fulfillment in India: A Preliminary Study," in Proceedings of the International Scientific Conference Environmental and Climate Technologies, CONECT 2015, pp. 429-434, Latvia, October 2015.

[37] M. R. Saavedra M., C. H. de O. Fontes, and F. G. M. Freires, "Sustainable and renewable energy supply chain: A system dynamics overview," Renewable \& Sustainable Energy Reviews, vol. 82, pp. 247-259, 2018.

[38] Q. Zhu, "Razumikhin-type theorem for stochastic functional differential equations with Lévy noise and Markov switching," International Journal of Control, vol. 90, no. 8, pp. 1703-1712, 2017.

[39] J. P. C. Bento and V. Moutinho, "CO2 emissions, non-renewable and renewable electricity production, economic growth, and international trade in Italy," Renewable \& Sustainable Energy Reviews, vol. 55, pp. 142-155, 2016.

[40] M. Verbič, S. Filipović, and M. Radovanović, "Electricity prices and energy intensity in Europe," Utilities Policy, vol. 47, pp. 5868, 2017.

[41] J.-M. Wang, Y.-F. Shi, X. Zhao, and X.-T. Zhang, "Factors Affecting Energy-Related Carbon Emissions in Beijing-TianjinHebei Region," Mathematical Problems in Engineering, vol. 2017, Article ID 1524023, 2017.

[42] L. Ji, S. Liang, S. Qu et al., "Greenhouse gas emission factors of purchased electricity from interconnected grids," Applied Energy, vol. 184, pp. 751-758, 2016.

[43] C. Zhang, K. Zhou, S. Yang, and Z. Shao, "On electricity consumption and economic growth in China," Renewable \& Sustainable Energy Reviews, vol. 76, pp. 353-368, 2017.

[44] Q. Zhu, "Average optimality for continuous-time Markov decision processes with a policy iteration approach," Journal of Mathematical Analysis and Applications, vol. 339, no. 1, pp. 691704, 2008.

[45] S. Gou, C. Wang, L. Zhang, M. Qiao, and Q. Wang, "Variations and influence factors of carbon emission of primary energy consumption from 1990 to, 2010, in Guangdong Province," Tropical Geography, vol. 4, pp. 389-394+401, 2012. 


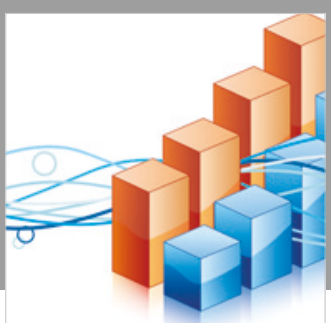

Advances in

Operations Research

\section{-n-m}
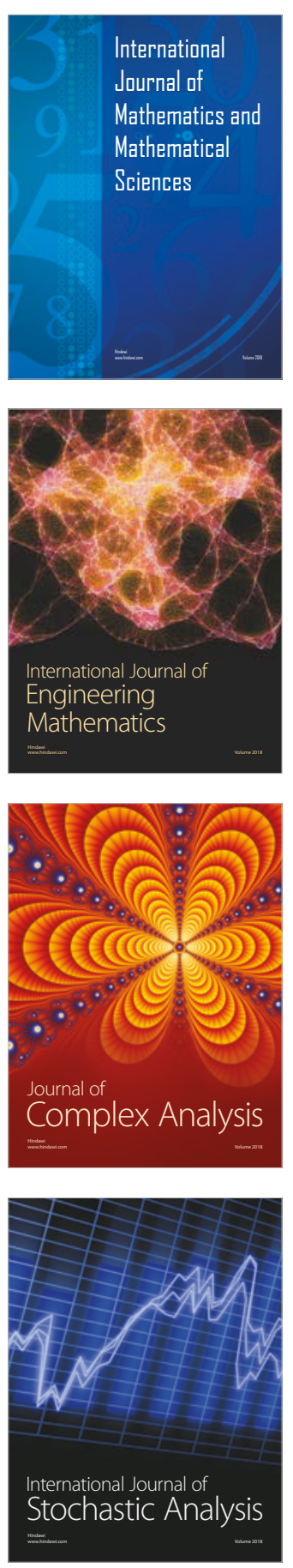
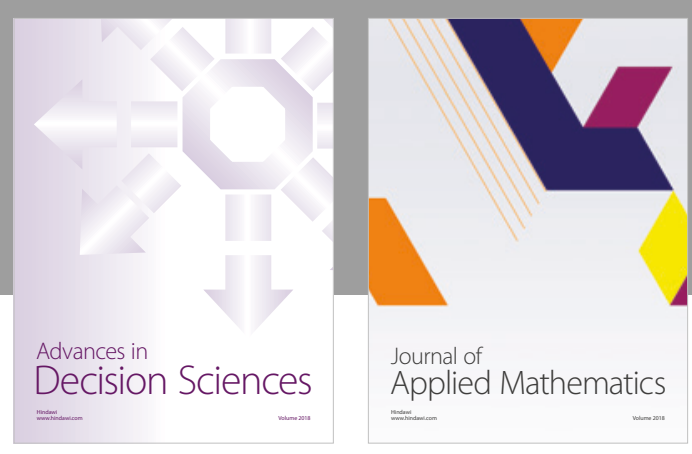

Journal of

Applied Mathematics
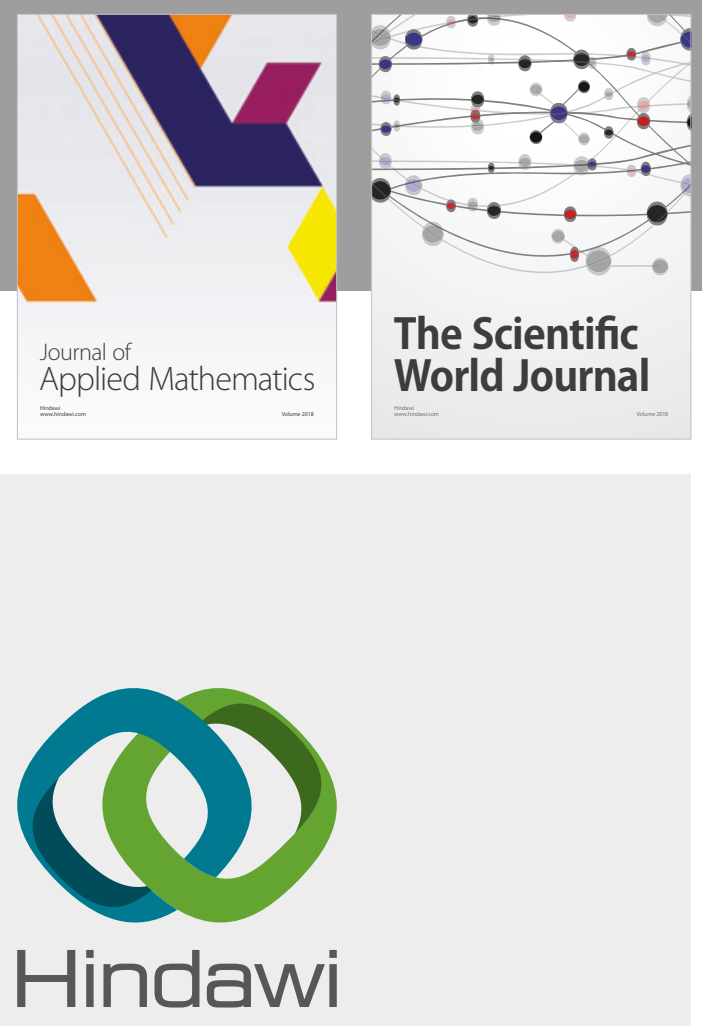

Submit your manuscripts at

www.hindawi.com

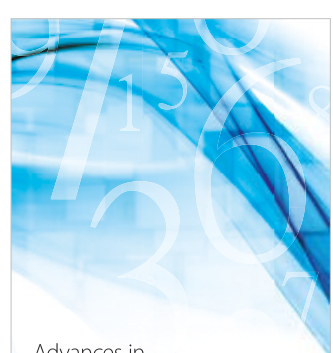

Advances in
Numerical Analysis
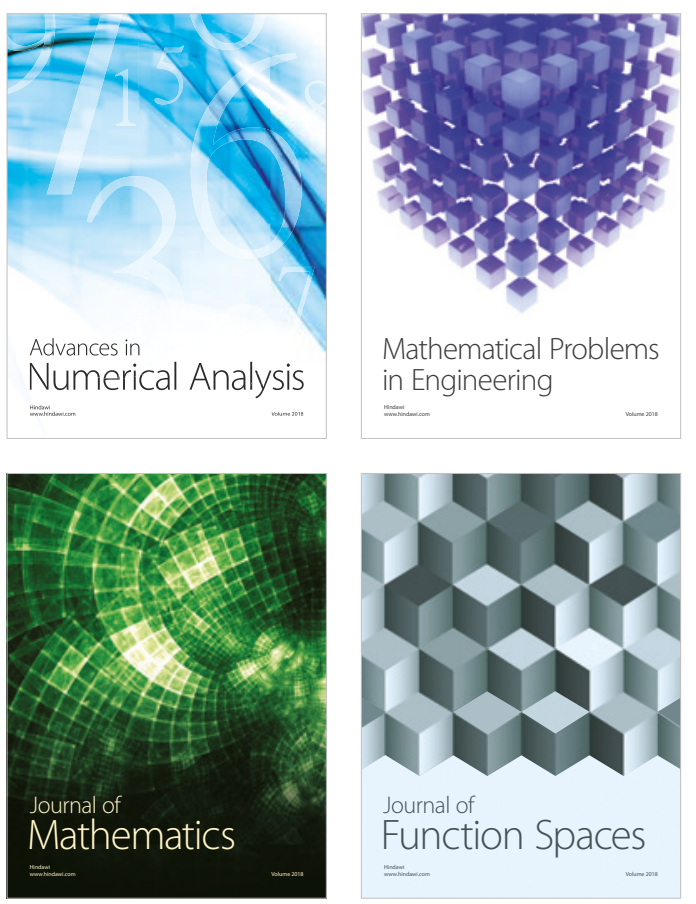

Mathematical Problems in Engineering

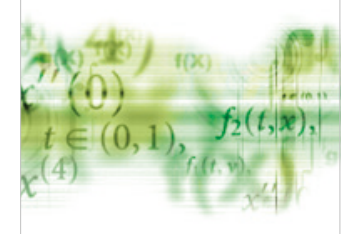

International Journal of

Differential Equations

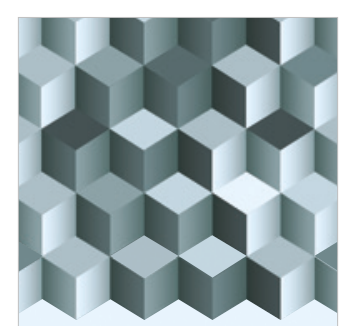

Journal of

Function Spaces

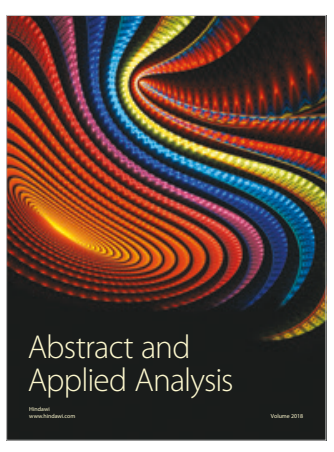

The Scientific

World Journal

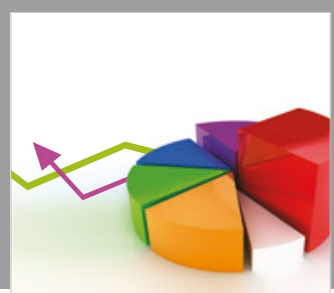

Journal of

Probability and Statistics
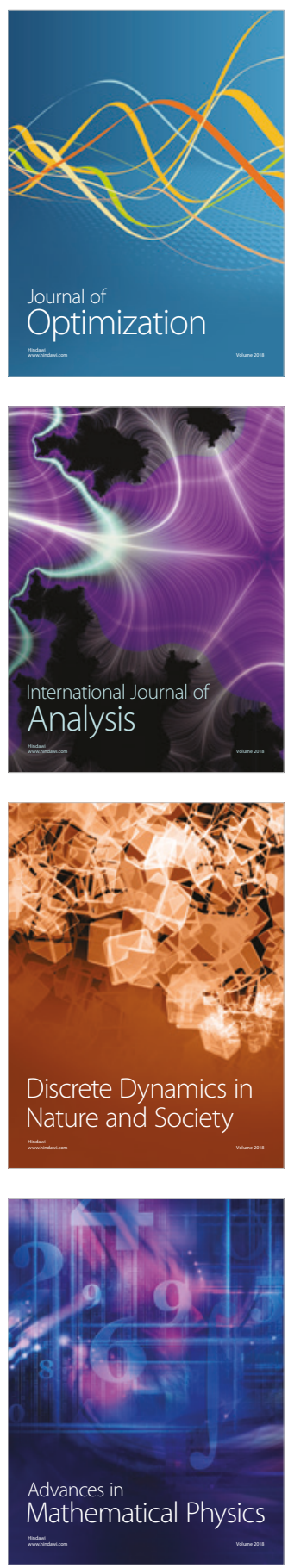